\title{
Everyday communications in religious practices
}

\author{
Lidiia Gazniuk ${ }^{1} *$, Irina Soina $^{2}$, Gennadiy Goncharov ${ }^{2}$, and Pavel Chervony ${ }^{2}$ \\ ${ }^{1}$ Belgorod State National Research University, 308015, Belgorod, Russia \\ ${ }^{2}$ Kharkov State Academy of Physical Culture, 61118, Kharkov, Ukraine
}

\begin{abstract}
It has been determined that understanding everyday life as a socially determined sphere of religious life makes it possible to explore the religious practices of the Orthodox believer, on the one hand, as a component of social relationships and a way of incorporating into religious relations, on the other, as a means of objectifying religious experience. Within the framework of various scientific areas, communication is explored as a way to transfer information in interpersonal, group and social interaction. Communication is considered as a way of being of everyday life, a universal form of sociality, reproduced in intersubjective interaction. The everyday relations of Orthodox believers are characterized by common linguistic meanings and processes of interpretation. The identification of religious individuals and communities takes place through communication. Daily life is the basis of the communication of believers, the religious language is the main factor in the nature of everyday life level. The influence on the development of religious relations of the newest means of communication, including Internet forums, providing the opportunity for communion of the laity, clergy, monastics, believers of other faiths and religions is shown.
\end{abstract}

\section{Introduction}

Everyday life of a believer is due to its inherent special paradigm of perception of the world as created by God, dominating the theological setting in consciousness. In modern conditions, the main role in the organization of daily communications of Orthodox believers belongs to religious communities. As the primary unit of the institutional structure, the Orthodox community is an association of believers, subjects of religious practices. In the context of everyday life, religious practices are largely determined by the presence of common linguistic meanings and the semantics of interpretation processes. Interpretation of the deep meanings of the living space, its understanding for the purpose of immersion into the surrounding reality, as well as the interpretation of the supernatural world is a natural desire of man. Considering this, everyday life as a peculiar system of social relations cannot exist outside of communication, which arises in the process of transferring information in interpersonal, group and social interaction, aimed at establishing mutual understanding.

The purpose of the article is to explore everyday communications in the religious practices of the Orthodox believer. Empirical conditions of human interaction, social forms

${ }^{*}$ Corresponding author: gazniuk@bsu.edu.ru 
of existence are embedded in a certain symbolic universal sphere, which language represents. The linguistic picture of the world (speech worldview) is studied within the framework of the hypothesis of linguistic relativity by E. Sapir and B. Whorf, who believe that linguistic forms have the opposite effect on the perceptual, mental and cognitive processes in general, forming an ethno-specific worldview. The theory of Sapir-Whorf states that the alleged division of the world, the formation of a system of concepts in which the world is understood, occurs according to the system of categories of natural language used by subjects of knowledge. According to E. Sapir, the real world is largely built on the basis of the language norms of this group. According to the theory of linguistic relativity, the type of language determines not only the forms of behavior of the language collective, but also the type of culture, type of thinking, that is, the logic adopted in culture (Sapir, 1993).). So, speech is not only means of expression, but also a form that determines the way of thinking of a person. The system of moral and ethical, value and ideological attitudes in society is structured through language. According to N. Luhmann's concept, communication is the leading concept in the theory of society, with which he proposes to change the wording of sociological theory, taking the concept of a system instead of the concept of action. The social system in this case appears to be an operatively closed system consisting of its own operations, it creates communication on communications. The presence of communication in society gives it a special systemic character. "Society," writes N. Luhmann, "is a communicatively closed system. It creates communication through communication. It can only communicate none saving - but not with itself and not with its surrounding world. It produces its unity through the operational implementation of communications, recursively addressed to the previous ones, and those that are ahead of the following communications" (Luhmann, 1999, p.223). Communicative relationships cover a wide range of phenomena of sociocultural reality, including the daily life of a believer. A multifaceted concept that accumulates powerful theoretical resources of philosophical and sociological thought is the theory of the communicative action of J. Habermas as a result of the search for grounds capable of ensuring mutual understanding and integration of social subjects. According to J. Habermas, the "life world" (Lebenswelt) as a system of sociocultural knowledge has an inter-subjective character. The life world is an organized store of knowledge, concentrated in culture, primarily in the language, passed on from generation to generation through cultural traditions. This stock of knowledge is the basis of the life experience of the individual. Unlike E. Husserl, J. Habermas believes that the structures of the life world are not defined only by the intentions of the transcendental ego, but are constructed by knowledge and experience embedded in culture and language (Habermas, 2004). This knowledge is mostly unobvious and unconscious, therefore it exists in a hidden form, manifesting itself in situational forms of communication.

The life world is comprehended in the process of its communicative interpretation, being organized with the help of the means of language and speech, associated with a particular cultural tradition. The totality of the procedures and institutes of communication forms the system of reproduction of the basis of the vital world and acts as the social world of everyday life. Therefore, the understanding of everyday life J. Habermas bases on the concept of "life" as the unity and homogeneity of consciousness and the subject. The search for meaning is solved by referring to the language as an ontological science and an epistemological construct. It is obvious that the language influences the ideological foundations of the faith and to a large extent determines the nuances of the communication systems of the Orthodox churches. The natural emotionality of Orthodox believers contributes to the spread of secular motifs in the communication system. The elements of emotional mass communication in Orthodoxy are pilgrimage to holy places, religious processions, church singing, prayer. An integral element of the communication of Orthodox believers is the iconography that binds the liturgy, the prayer and the temple complex. 
Today, the Orthodox communication system is filled with new means of communication (television, Internet sites). Live speech, that is, speech in its manifestations and application, according to M. Heidegger, is the ontological basis of all other aspects of the language. Speech is the basis of language. (Heidegger, 1993, p.279). The philosopher defines the basic phenomena of speech - hearing, silence, gossip, language. According to M. Heidegger, speech is a poetry capable to discover new Dasein possibilities, therefore it manifests itself as a "modus" of aging and "manifestation" of Dasein. Language has its own being while it develops, acquires new meanings, words, turns. It changes as it is pronounced, explains Dasein. Thus, language is the modus of existence of Dasein and its existential structure.

The modified everyday life "Dasein" appears in M. Heidegger as the world of caring action, the way in which being exists here, which is connected with the world with the help of tuned understanding, although in the modus of everyday life, being reveals lack of this understanding. In general, with negative attitude to everyday life, the scientist notes that every day life is a "native way of life here being", that is the present being. A person learns about many things for the first time in the modus of everyday interpretation, as there is much that never rises above everyday understanding (Heidegger, 1993, p.33). According to M. Heidegger, the existential-ontological foundation of language is speech, which leads understanding in the process of communication. The daily life of a believer is characterized by the peculiarities of communication, whose functions are to organize everyday life with the help of transmitted knowledge, mastering the rules, norms and values adopted in a given society, meeting the needs of various levels with the help of daily interactions. The study of everyday communications and social structures within which they take place is necessary to clarify the features of the functioning of religious communication in the context of the daily life of the Orthodox believer. In the process of understanding a religious language, it is important to combine methods of empirical, rational, and mysticintuitive knowledge with the support on grammar, psychology, logic, and spiritual disciplines. The church life of Orthodox believers presupposes not only participation in worship services and individual ascetic practice, which consists in following certain rules and prohibitions as directions of the spiritual development of the human person.

In the study of communicative attitudes of believers, the provision of social communication as an organization of speech acts and mutual understanding of subjects is of significant cognitive importance. According to G. Garfinkel, social reality is "constructed" in the process of speech communication. Identifying social interaction with language communication, he draws attention not to the content, but to the norms of communication. Social becomes possible only due to the fact that the subjects communicate according to certain "rules of speaking". In the usual "conversation" of subjects there are elements of mutual understanding, which is established not only on the basis of what was said, but also on the basis of the unspoken. That is, understanding is often achieved as a result of not actual clarification, but the presence of a certain temporal sequence of speech, patterns of thought's expression. The "background expectations" lie in the sense of the respective reaction of the partners, which clarifies the meaning of speech, the positions of the subjects and the assessment. Any violation of these expectations can destroy communication. Background expectations that people sometimes unconsciously guide in their actions, according to ethnomethodology, manifest themselves in unusual versions of ordinary situations (Garfinkel, 2007).

Considering the findings of ethnomethodology, we note that the nature of religious communication largely depends on the availability of a common direction of the community of believers. In modern parishes, where priests actively work with believers, organize Sunday schools for children and adults, groups of combined reading of the Gospel, thematic seminars and discussions, joint pilgrimages, actions of charity, family or children's 
summer camps, etc. So real communities of believers are appeared. They consist of a wide range of worshipers, similar to large families with strong internal connections and mutual assistance. Therefore, socialization within the Orthodox community implies a person's willingness to take part in the cultural tradition of the country, to accept patterns of behavior that exist in it, and thus accept the identity that expected and constructed from other traditions. In studying the interpersonal communication of believers, an important role is played by Giddens' scientific conclusions, for which the immediate social interactions of people are a social reality, primarily in situations of "co-presence". This is not about communication as speech communication, which is dominated by supra-individual sign systems, but about communication that arises from direct interpersonal exchanges of messages. The situation of sign face-to-face exchanges is the ultimate element of reality, and their diversity constitutes sociality. Within each individual communicative situation, sign metasystems, including phonetic speech, play an insignificant role along with a plurality of other languages involved in communication.

The sign of gestures, columniations, reservations, exclamations, views, observations of the details of the situation are of more importance than the language of words. That is, silent behavioral reactions in each case have the nature of signs. For Giddens, therefore, the more important are not the linguistic elements, but the situational context to which people react through the use of language. Due to the unavoidable contextuality of communication, language metasystems can easily change their semantics, so information cannot be read outside this context (Giddens, 2005). It is within the specific communicative situations of "co-presence," according to E. Giddens, the communication takes place and it is of crucial structural importance in society.

Representatives of symbolic interactionism focus on studying the world of small groups, interpersonal and intra-group interactions. So, the main thing in the teaching of $\mathrm{J}$. Mead is the concept of inter-individual interaction, which is closely related to the category of social act, considered as a dialogue between individuals, a constant exchange of attitudes and actions. Considering the social act as an interaction, it defines non-symbolic and symbolic interaction. The first means the direct reaction of people to the actions of each other, but in the process of the second there is an exchange of "attitudes, sense and meanings" using various forms of communication, primarily language (Mead, 2005). J. Mead provides of particular importance an analysis of voice gesture and its transformation into a symbol of interaction. Language as a set and interrelation of voice gestures performs the function of coordinating human behavior. It is obvious that speech and other significant symbols coordinate the behavior of people only in the status of the common heritage of a community whose members never communicate in the same language. For this reason, situations of misunderstanding can cause disruption of interaction. So, symbolic interactionism has a realistic view of the interaction between people, but focuses only on the subjective aspects of interaction concerning the communication of specific individuals in a particular situation.

U. Eco proposed a standard applied communication model, reinforced by the concept of lexical codes or secondary codes, which he understands as additional connotative meanings that are not known to everyone, but only parts of the audience (Eco, 1998, p.74). Thus, analyzing early Christianity, U. Eco noted that in order to increase his influence he had to invent parables and symbols, which pure theory cannot do. For example, Jesus was symbolized by the image of a fish (Eco, 1986, p.54). Communicative beginning, provokes the individual to enter into communicative interaction in the role of addresser or addressee, and it is present in each text. For this reason, any text that a person possesses is the result of previous communicative interactions and communicative events (Beaugrande, 1994, p.10).

The main components of the communication system of Christian denominations include: verbal communication (oral and written speech, canonical texts, typography, 
prayer, confession, preaching) and non-verbal communication (facial expressions, gesticulation, color, clothing, temple, icon, etc.), mixed communication, which is most often used in modern Christianity, event communication. In modern conditions, there is a gradual decrease in the role of traditional forms of religious communication, but the media are increasingly claiming to be the main sources of information. Spiritual life, in addition to the accumulation of religious knowledge and the implementation of religious practices, provides for the acquisition of personal spiritual experience. Externally, the practices of religious life for all are the same: there is a routine of posts generally accepted for all lay people, the recommended frequency of communion, and the like. However, over time, the believer changes the perception of religious norms, overestimating their meaning and significance. Therefore, the ethos of modern Orthodoxy can not be considered fully prescribed. In the case of a particular person, it largely depends on the personal preferences and inclinations of the person himself, that is, on his character and social habit and on the cultural characteristics of the local Orthodox community. Therefore, the life of the bearer of the Orthodox tradition is not totally rationed, with the exception of the content and sequence of worship services. Due to this circumstance, a modern believer in the case of pilgrimage or long-term migration can feel comfortable in any church, become a full participant in the process. Arising in the process of a certain situation, speech becomes independent, maintaining its structure even after the disappearance of these situations from life. Speech must be understood as a specific slice of the history of society and culture. There is not a single "individual" colloquial speech, since it has a group character (Kasavin, 1991). The colloquial function of an ordinary language always implies the interlocutor, that is, a live communicative discourse.

\section{Conclusion}

Thus, communication appears as a way of being of everyday life, a mechanism for the development of social interactions in the context of everyday life. The obvious defining role of communication in the formation of not only the form, but also the content of the everyday life of the believer. Communication arises as a universal form of sociality, and is reproduced in intersubjective interactions. In religious practices and interactions through language, the process of identification of individuals, groups, communities takes place. In modern conditions, the religious practices of Orthodox believers are characterized by the transformations of communication under the influence of the latest technologies, changes in psychology, accompanied by the intensification of communication processes in society.

\section{References}

1. R. Beaugrande, Text Linguistics. The Encyclopedia of Language and Linguistics (Pergamon Press, Oxford, New York, Seoul, Tokyo, 1994).

2. U. Eco, Absent structure. Introduction to semiology (Petropolis, S.-Petersburg, 1998).

3. U. Eco, Art and Beauty in the Middle Ages (Gnosis. Moscow, 1986).

4. G. Garfinkel, Research on ethnomethodology (Piter, S.-Petersburg, 2007).

5. E. Giddens, Sociology (Editorial URSS, Moscow, 2005).

6. J. Habermas, A lecture on the life world, (2004). Retrieved on 2 June 2016 from http://russia.ru/video/nauka_habermas/.

7. M. Heidegger, Works and reflections of different years (Gnosis, Moscow, 1993).

8. I. T. Kasavin, Analysis of everyday life (Progress, Moscow, 1991). 
9. N. Luhmann, Theory of society: fundamental problems (Canon-Press-C- Kuchkovo Pole. Moscow, 1999).

10. J. Mead, From gesture to symbol, (2005). Retrieved on 23 November 2014 from http://www.gumer.info/nfo/bogoslov_Buks/Philos/Article/Mid_GestSi.php.

11. E. Sapir, Selected Works on Linguistics and Cultural Studies (Progress, Moscow, 1993). 